\title{
OBJETO DE APRENDIZAGEM TRABALHO COM PROJETOS
}

\author{
Silvia F. S. Moresco ${ }^{a}$ [ferreto@netp.com.br] \\ Doutoranda do Programa de Pós-Graduação em Educação \\ Patricia Alejandra Behar ${ }^{\mathrm{b}}$ [pbehar@terra.com.br] \\ Professora Orientadora do Programa de Pós-Graduação em Educação \\ a /b Núcleo de Tecnologia Digital Aplicada à Educação \\ FACED - Faculdade de Educação \\ UFRGS - Universidade Federal do Rio Grande do Sul \\ Av. Paulo da Gama, 110 - Prédio 12105 - Anexo I Reitoria - 4to. \\ andar
}

Campus Central - CEP: 90.046-900 - Porto Alegre- RS -Brasil.

Resumo: O Objeto de Aprendizagem Trabalho com Projetos é uma entidade digital desenvolvida com o objetivo de divulgar informação, promover a construção de conhecimentos e possibilitar a tomada de consciência de professores em formação continuada de todas as áreas de estudo, que interagem através das tecnologias digitais. Através dele pretende-se criar um espaço de autoformação participada que invista no professor como produtor de saberes. Para isso, o objeto disponibiliza aos seus usuários doze recursos pedagógicos. São eles: Banco de desafios, Desenvolvimento de Projetos, Interdisciplinaridade, Concepções Teóricas, Biblioteca Virtual, Videoteca, Sites Interessantes, Bate-Papo, Glossário, Mural, Feedback e Ajuda. Sua interface apresenta similaridade com uma sala de professores. Através dessa metáfora, busca-se uma transferência de significados do meio presencial para o meio virtual, com o propósito de convidar o professor a ocupar o espaço digital.

Palavras-chave: Objeto de Aprendizagem, Projetos, Formação Continuada, Tomada de Consciência

Abstract: The Learning Object "Trabalho com Projetos" (Work with Projects) is a digital entity developed with the objective to divulge information, to promote the construction of knowledge and to make possible the taking of conscience of teachers in continued formation of all the study areas, that interact through the digital technologies. Through it one, intends to create a space of participated self-formation that it invests in the professor as producing to know. For this, the object offers to its users twelve pedagogical resources. They are: Bank of challenges, Development of Projects, Theoretical Conceptions, Interdisciplinarity, Virtual Library, Videos, Interesting Websites, Chat, Glossary, Messages, Feedback and Help. Its interface presents similarity with a teacher's room. Through this metaphor, a transference of meanings of the actual way for the virtual way searchs, with the intention to invite the teacher to occupy the virtual space.

Keywords: Learning Objects, Projects, Continued Formation, Taking of Conscience 


\section{Introdução}

O Objeto de Aprendizagem Trabalho com Projetos se baseia em pressupostos interacionistas. Essa ferramenta possibilita uma participação ativa do aprendiz na construção e no seu desenvolvimento cognitivo. O Objeto pode ser utilizado em situações de aprendizagem tanto na modalidade presencial como à distância.

Este objeto tem como principal objetivo possibilitar o processo de tomada de consciência de professores em formação continuada. Para tanto, propõe-se atividades que exploram diferentes recursos tecnológicos e que podem ser empregados em diferentes campos de atuação, visando a instrumentalização teórica e prática do professor.

Para o desenvolvimento deste objeto, consideraram-se tanto os aspectos educacionais quanto estéticos e tecnológicos. Desta forma, pretende-se oferecer ao usuário uma ferramenta de fácil navegação e agradável experiência estética, de forma que os objetivos educacionais possam ser atendidos.

Nessa perspectiva, o presente artigo define o Objeto de Aprendizagem Trabalho com Projetos, apontando seus objetivos e concepções teóricas. Ele também apresenta a metáfora adotada, justificando as razões para o seu uso da metáfora. Na sequiência apresenta os recursos pedagógicos disponibilizados pelo OA e suas respectivas funções. Finalmente têm-se as considerações finais.

\section{Objeto de Aprendizagem Trabalho com Projetos}

O Objeto de Aprendizagem Trabalho com Projetos ${ }^{1}$ foi desenvolvido conforme a proposta de objetos de aprendizagem do Projeto CESTA (Coletânea de Entidades de Suporte ao uso de Tecnologia na Aprendizagem), disponível em: http://www.cinted.ufrgs.br/CESTA/cestadescr.html.

Os objetos de aprendizagem (OA) são definidos por Coscarelli ${ }^{2}$ (2004) da seguinte forma:

Os objetos de aprendizagem são pequenos instrumentos, na maioria das vezes digitais, que podem ser utilizados diversas vezes. Podem ser vídeos, imagens, figuras, gráficos e outros que são disponibilizados para auxiliar na aprendizagem dos alunos. Uma animação onde um trapezista aparece caindo pode auxiliar o aluno a entender um pouco melhor os conceitos da Física, por exemplo. O aluno utiliza a animação para calcular e fazer inúmeros testes, como aumentar o peso do atleta, modificar a altura da queda e, assim, visualizar o resultado (p.1).

\footnotetext{
${ }^{1}$ Este é um dos objetos desenvolvidos no Projeto Instrumentalização em EAD - Edital 05_2005/ SEAD/UFRGS. Disponível em: http://www.universia.com.br/html/materia/materia dacf.html . Acessado em: 14/10/2004.

${ }^{2}$ COSCARELLI, Crislaine. Objetos para aprender fazendo. Disponível em: http://www.universia.com.br/html/materia/materia dacf.html . Acessado em: 14/10/2004. 
Nessa perspectiva, define-se o Objeto de Aprendizagem Trabalho com Projetos ${ }^{3}$ como uma entidade digital utilizada para divulgar informação, promover a construção de conhecimentos e possibilitar a tomada de consciência de professores em formação continuada, que interagem através das tecnologias digitais. Trata-se de um recurso metodológico, desenvolvido pela autora juntamente com a equipe do NUTED ${ }^{4}$, para ser utilizado em cursos de formação continuada de professores.

Esse objeto de aprendizagem foi idealizado para professores de todas as áreas de estudo. Ele tem os seguintes objetivos: a) proporcionar, ao professor em formação continuada, uma aprendizagem significativa sobre os diferentes tipos de projetos que podem ser desenvolvidos no ambiente escolar; b) promover discussões e reflexões sobre diferentes questões que envolvem o trabalho com projetos em educação, visando possibilitar a tomada de consciência sobre o fazer pedagógico; c) promover a elaboração e execução de projetos educacionais por parte dos professores participantes; d) possibilitar uma formação continuada crítica e reflexiva, criando condições para o pensamento autônomo; e) possibilitar um espaço de autoformação participada que invista no professor como produtor de saberes.

Em relação ao design do Objeto de Aprendizagem Trabalho com Projetos, sua interface apresenta similaridade com uma sala de professores. Através dessa metáfora ${ }^{5}$, pretende-se propiciar uma transferência de significados do meio presencial para o meio virtual, com o objetivo de convidar o professor a ocupar o espaço digital.

A figura 1 mostrada a seguir ilustra a página principal do Objeto de Aprendizagem Trabalho com Projetos.

\footnotetext{
${ }^{3}$ Este conceito foi elaborado pela autora com base no artigo "Objetos de Aprendizado: Um novo modelo direcionado ao Ensino a Distância", publicado em 17/12/2004, no site Universia Brasil, disponível em: http://www.universia.com.br/materia/materia.jsp?id=5938. Acessado em: 12/10/2006.

${ }^{4}$ Núcleo de Tecnologia Digital Aplicado à Educação - FACED - UFRGS. A Equipe que desenvolveu o "Objeto de Aprendizagem Trabalho com Projetos" é composta pelos seguintes membros: Suelen Alves da Silva, André Martins Ressel e Silvia Ferreto da Silva Moresco, sob a orientação: da Profa. Patricia Alejandra Behar.

${ }^{5}$ A metáfora é "a transferência de significado de uma zona para a outra que lhe é estranha desde o início". Site da TV Cultura - Fundação Padre Anchieta - ALÔ ESCOLA - Glossário de Termos Técnicos. Disponível em: http://www.tvcultura.com.br/aloescola/literatura/poesias/glossario.htm. Acessado em: 13/10/2006.
} 


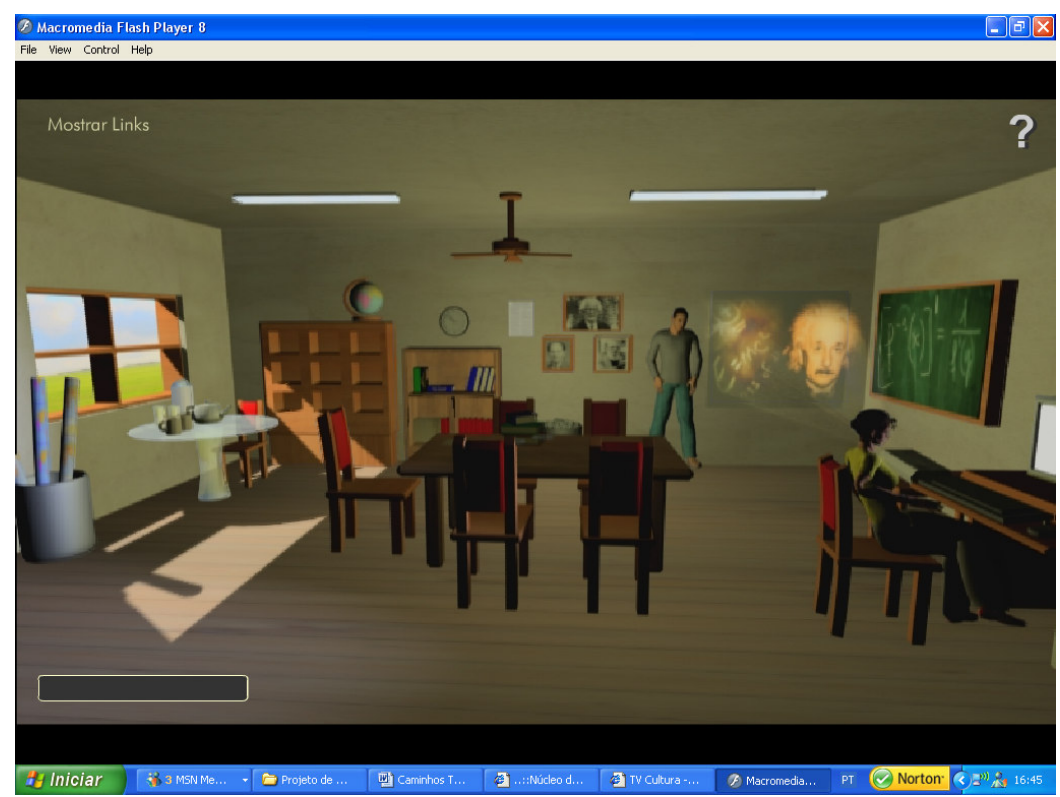
Projetos

Figura 1 - Interface principal do Objeto de Aprendizagem Trabalho com

A seguir apresentam-se os recursos pedagógicos disponibilizados pelo Objeto de Aprendizagem Trabalho com Projetos.

\section{Recursos Pedagógicos}

Para isso, foram elaborados doze recursos pedagógicos. São eles: Banco de Desafios, Desenvolvimento de Projetos, Interdisciplinaridade, Concepções Teóricas, Biblioteca Virtual, Videoteca, Glossário, Sites Interessantes, Bate-Papo, Mural, Feedback e Ajuda.

Como a proposta deste Objeto de Aprendizagem é desafiar os professores em formação continuada a resolver problemas abertos ${ }^{6}$, nomeados pela autora como desafios. Estes representam uma atividade cognitiva e motivacional, constituindo um meio ou recurso instrumental para alcançar um objetivo. Para a solução de desafios são exigidas diferentes estratégias, conhecimentos conceituais, práticos, atitudes e outros fatores. Durante a solução, os sujeitos envolvidos podem refletir sobre o conteúdo que está sendo estudado e, também sobre os processos ou passos utilizados por eles para a resolução. Dessa forma, coloca-se em ação uma ampla série de habilidades e conhecimentos (POZO, 1998).

\footnotetext{
${ }^{6}$ OS problemas abertos se caracterizam por se apoiar amplamente na resolução literal e não fornecer dados. Implicam a realização de um estudo qualitativo da situação em questão, com emissão de hipóteses

cerca dos fatores de que pode depender a incógnita solicitada e a formulação de estratégias de resolução a partir do repertório teórico (PIETROCOLA, 200, p. 111).
} 
A metodologia dos desafios foi utilizada, com a intenção de privilegiar a construção coletiva de conhecimentos a partir do questionamento, problematização, discussão, reflexão crítica, apresentação de dúvidas e troca permanente de informações. Aprender é, neste modelo, envolver-se na troca coletiva e comunitária, contribuindo e recebendo, refletindo e instigando os colegas, buscando colocar em funcionamento uma inteligência coletiva. A metodologia dos desafios foi adotada, visando a formação de sujeitos autores, com atuação autônoma e responsável, tanto no ambiente de formação como em sala de aula.

Nóvoa (1992) afirma que os professores constroem seus saberes de forma ativa, sugere redes de autoformação participativa, que possibilitem a compreensão da totalidade do sujeito, considerando a formação um processo dinâmico e interativo. Ele defende a necessidade de investir na prática docente como um espaço de produção de saberes. Considerando essa perspectiva, entende-se que a resolução de desafios, como atividade cognitiva, motivacional e, consequentemente, construtiva, pode ajudar os professores no processo de tomada de consciência do seu fazer pedagógico, bem como abrir um importante espaço de produção de saberes. A Figura 2, apresentada a seguir, ilustra o recurso pedagógico "Desafios".

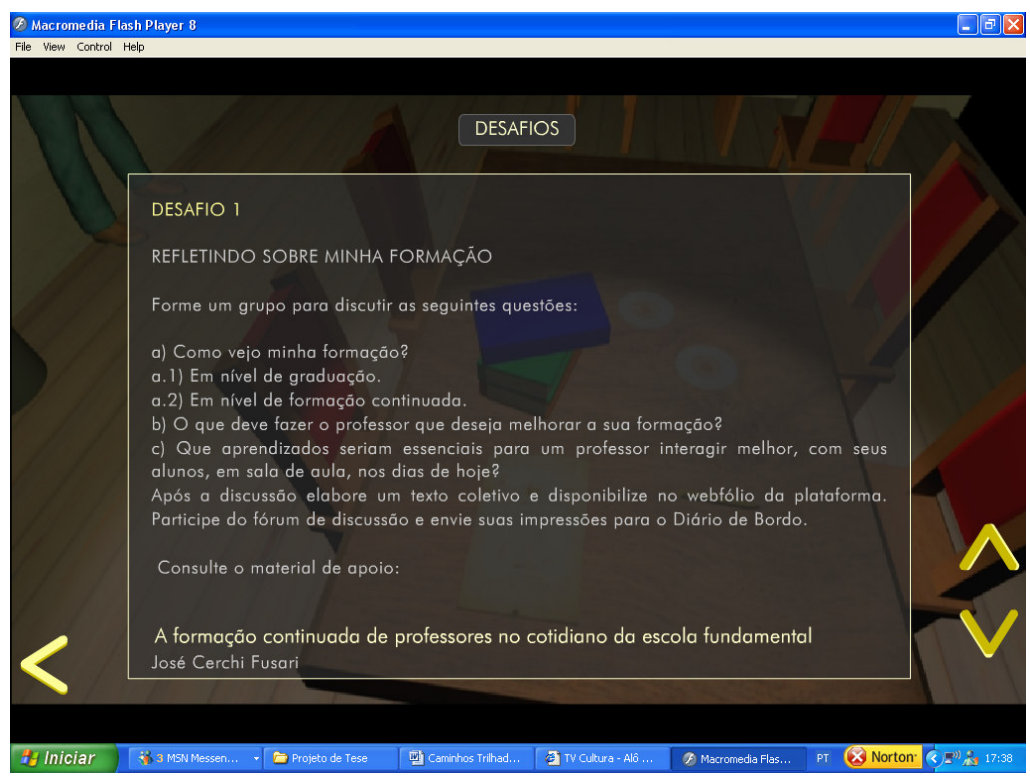

Figura 2 - Desafios do Objeto de Aprendizagem Trabalho com Projetos

O recurso pedagógico "Desenvolvendo Projetos" foi especialmente elaborado para dar suporte teórico a criação, organização e edição de projetos educacionais. A seguir pode-se observar a figura 3, que ilustra o recurso pedagógico "Desenvolvendo projetos". 


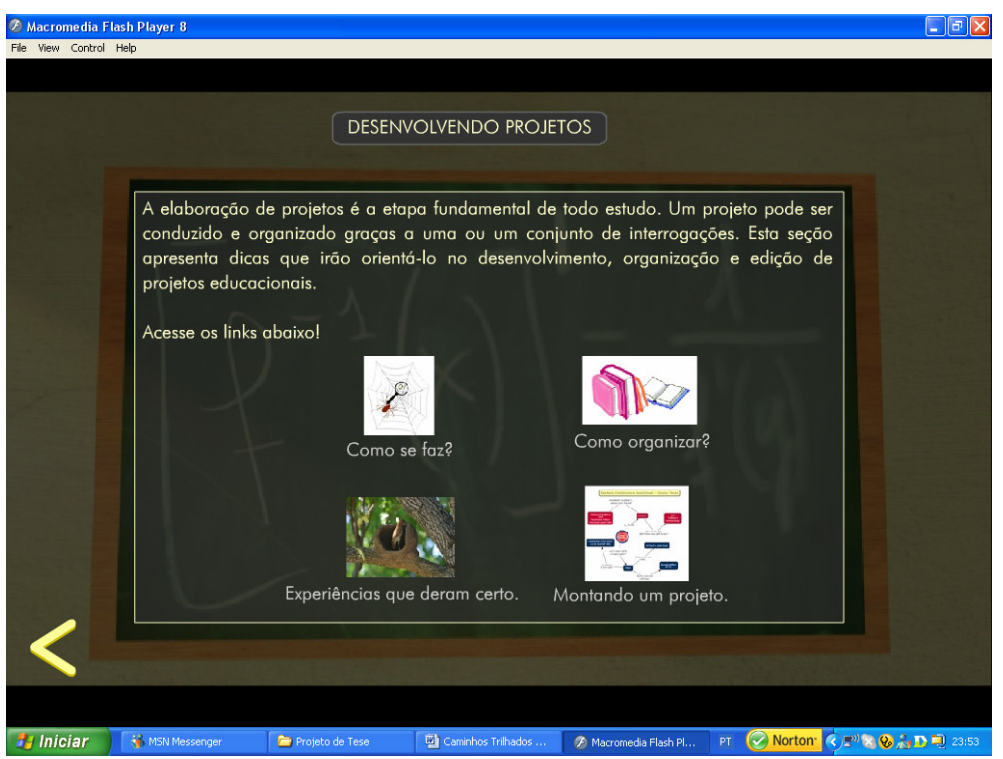

Figura 3 - Desenvolvendo projetos do Objeto de Aprendizagem Trabalho com Projetos

O recurso pedagógico "Interdisciplinaridade", como o nome sugere, apresenta material de suporte aos estudos interdisciplinares, abrindo um espaço para discussões e reflexões relacionadas com este tema. Aborda-se esse assunto, pois atualmente no plano prático, surgem projetos educacionais que reivindicam uma visão interdisciplinar no campo curricular. Com base nos estudos realizados por Fazenda (1979), o material disponibilizado propõe a construção do conhecimento globalizante, rompendo com as fronteiras das disciplinas. Ele traz a idéia que somente integrar conteúdos curriculares não seria suficiente para desenvolver um projeto educacional interdisciplinar, o professor precisa ir além e adotar uma postura interdisciplinar.

O recurso pedagógico "Concepções Teóricas" foi elaborado com o objetivo de disponibilizar informações sobre a vida e a obra de Jean Piaget, David Paul Ausubel e Paulo Freire. Esses três estudiosos contribuíram para a pedagogia contemporânea, rompendo com a educação tradicional e apontando para a construção de novos paradigmas educacionais. Seus exemplos, suas descobertas e perspectivas teóricas podem apoiar o planejamento, implementação e avaliação de projetos educacionais, bem como o fazer docente em sala de aula.

Os sujeitos envolvidos no curso de formação continuada, além dos materiais pedagógicos já apresentados poderão contar ainda, com uma "Biblioteca Virtual". Ela apresenta uma coletânea de referenciais que reúnem e organizam informações sobre projetos educacionais e assuntos relacionados com esse tema. Esses materiais estão disponíveis no ambiente Web. A figura 4 apresenta a interface deste recurso. 


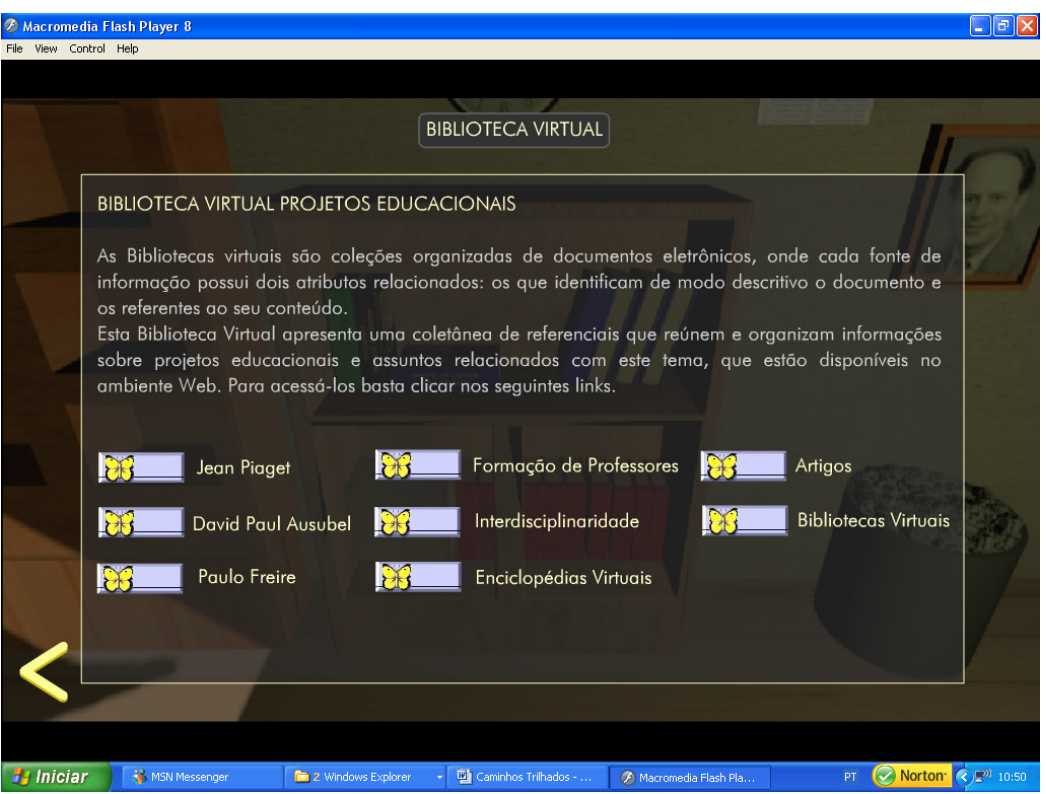

Figura 4 - Biblioteca Virtual do Objeto de Aprendizagem Trabalho com Projetos

O OA Trabalho com Projetos dispõe de uma "Videoteca" que visa atuar como apoio pedagógico na formação de professores, tanto em nível de graduação como em nível de formação continuada. Ela apresenta uma seleção de vídeos e áudios relacionados com o tema "projetos educacionais".

Pode-se encontrar também, neste objeto de aprendizagem, um espaço virtual chamado "Sites Interessantes". Esse espaço apresenta uma seleção de sites relacionados com o tema projetos educacionais e seus respectivos links, visando proporcionar apoio e leituras complementares durante as atividades propostas.

Com a finalidade de disponibilizar a terminologia do curso aos professores em formação, desenvolveu-se um glossário para o objeto. Em caso de dúvidas, basta que o sujeito acesse o glossário, selecione a letra inicial do termo desejado e, em seguida, faça a busca em ordem alfabética. .

Esse objeto também dispõe de um "Mural", no qual os participantes encontram lembretes e dicas que podem ajudar durante as atividades propostas.

O termo feedback ${ }^{7}$ está relacionado com o auto-controle de um sistema pela análise dos resultados obtidos. Nessa perspectiva, desenvolveu-se o recurso feedback para que os usuários do Objeto de Aprendizagem Trabalho com Projetos possam expressar sua opinião sobre o Objeto.

Com a finalidade de levantar parâmetros para avaliar o uso do Objeto de Aprendizagem Trabalho com Projetos, elaborou-se com base em Silva (2006), Valente

\footnotetext{
${ }^{7}$ Retroalimentação. Termo técnico da cibernética (cybernetics) relacionado com o auto-controle de um sistema pela análise dos resultados obtidos. Agora usado na EAD para qualquer forma de fluxo de informações do tutor ao aluno, ou de um gabarito de respostas pré-preparadas. Disponível em:

http://www.escolanet.com.br/dicionario/dicionario f.html . Acessado em: 24/10/2006.
} 
(2006) e Barros (2006) um instrumento de coleta de dados composto de dezessete questões.

A seguir pode-se observar a Figura 5 que ilustra este recurso.

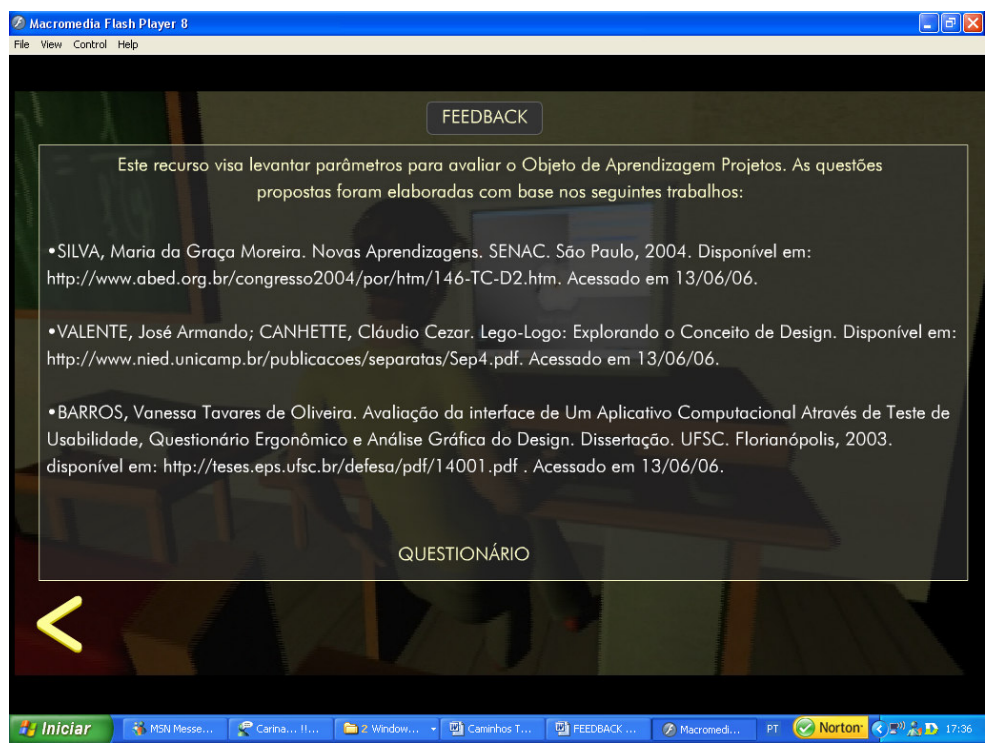

Figura 5 - Feedback do Objeto de Aprendizagem Trabalho com Projetos.

Finalmente, apresenta-se o recurso "Ajuda", no qual o professor em formação pode encontrar dicas de usabilidade do Objeto de Aprendizagem Trabalho com Projetos. Essas dicas podem ser muito úteis, pois permitem ao usuário uma visão global do objeto. A figura 6 ilustra o recurso Ajuda.

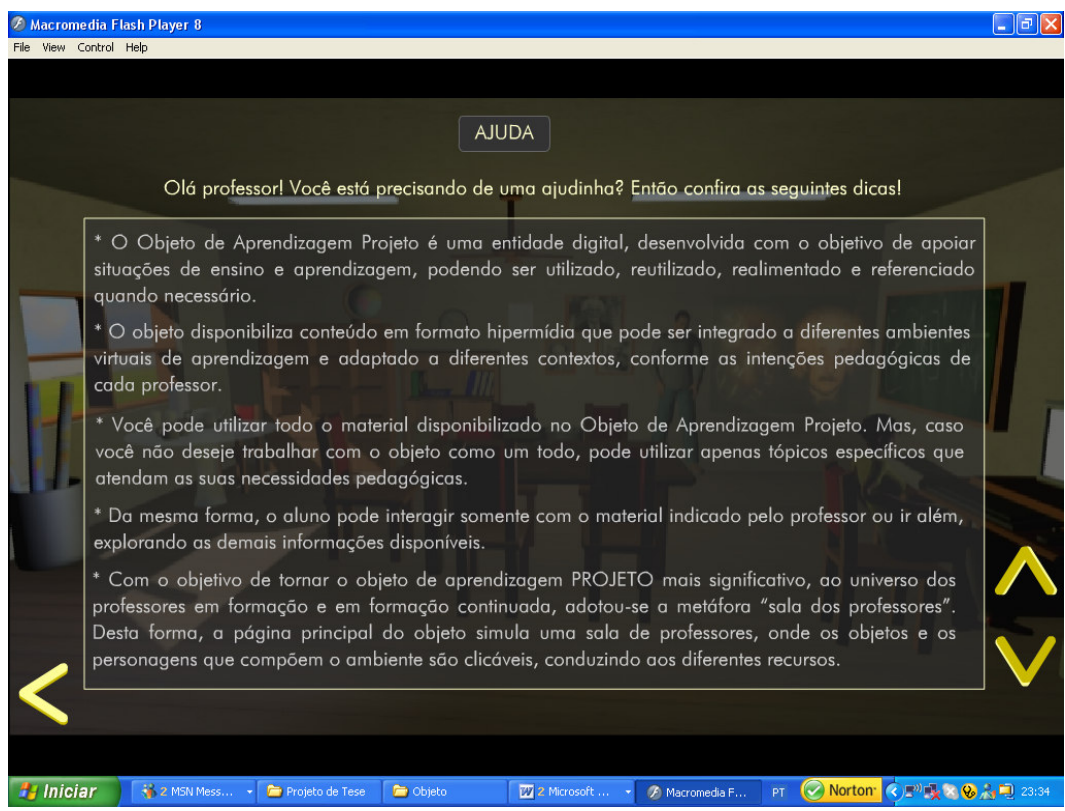

8 V. 4 № 2, Dezembro, 2006 
Figura 6 - Ajuda do Objeto de Aprendizagem Trabalho com Projetos

\section{Considerações Finais}

Considera-se que os objetos de aprendizagem são excelentes recursos digitais para auxiliar o processo de ensino e aprendizagem.

Nessa perspectiva, desenvolveu-se o Objeto de Aprendizagem Trabalho com Projetos idealizado para promover o processo de tomada de consciência e a articulação entre a formação continuada de professores e os projetos educacionais.

Através do seu uso, deseja-se possibilitar dinâmicas de autoformação participada que perpassem a pesquisa, a construção de saberes, a cooperação/colaboração, a tomada de consciência do fazer pedagógico e, consequentemente, o planejamento de novas maneiras de intervenção docente.

Este OA deverá ser utilizado durante o primeiro semestre de 2007, como proposta metodológica de um curso de formação continuada de professores da Rede Pública Estadual do Estado do Rio Grande do Sul.

Durante o curso de formação continuada, pretende-se testar o funcionamento do objeto, seu grau de adequação ao público-alvo e o nível de cumprimento dos seus objetivos.

\section{Referências}

ALÔ ESCOLA - Glossário de Termos Técnicos. Disponível em: http://www.tvcultura.com.br/aloescola/literatura/poesias/glossario.htm . Acessado em: 13 de outubro de 2006.

BARROS, Vanessa Tavares de Oliveira. Avaliação da interface de Um Aplicativo Computacional Através de Teste de Usabilidade, Questionário Ergonômico e Análise Gráfica do Design. Dissertação. UFSC. Florianópolis, 2003. Disponível em: http://teses.eps.ufsc.br/defesa/pdf/14001.pdf . Acessado em 13/06/06.

CESTA. Coletânea de Entidades de Suporte ao uso de Tecnologia na Aprendizagem. Disponível em: http://www.cinted.ufrgs.br/CESTA/cestadescr.html . Acessado em 26/9/2004.

COSCARELLI, Crislaine. Objetos para aprender fazendo. Disponível em: http://www.universiabrasil.net/materia imp.jsp?id-3025 . Acessado em: 14/10/2004. 
FAZENDA, Ivani. Interação e Interdisciplinaridade no ensino brasileiro: efetividade ou ideologia? São Paulo: Loyola, 1979.

NÓVOA, António. Os professores e sua formação. Liboa-Portugal: Dom Quixote, 1992.

PIETROCOLA, Maurício (org). Ensino de Física: conteúdo, metodologia e epistemologia. Florianópolis: Ed. Da UFSC, 2001.

POZO, Juan Ignácio. A solução de problemas: aprender e resolver, resolver para aprender. Porto Alegre: ArtMed, 1998.

SILVA, Maria da Graça Moreira. Novas Aprendizagens. SENAC. São Paulo, 2004. Disponível em: http://www.abed.org.br/congresso2004/por/htm/146-TC-D2.htm. Acessado em 13/06/06.

VALENTE, José Armando; CANHETTE, Cláudio Cezar. Lego-Logo: Explorando $o$ Conceito de Design. Disponível em: http://www.nied.unicamp.br/publicacoes/separatas/Sep4.pdf . Acessado em 13 de junho de 2006. 